\title{
RANCANG BANGUN TUNGKU PENGECORAN LOGAM ALUMINIUM
}

\author{
Minto $^{1}$, Sumarsono ${ }^{2}$, Fajar Satriya $\mathrm{Hadi}^{3}$, Meriana Wahyu Nugroho ${ }^{4}$ \\ Fakultas Teknik Universitas Hasyim Asy'ari \\ ${ }^{1}$ mintoiriuha@gmail.com \\ 2 sonsumarsono13@gmail.com \\ ${ }^{3}$ Satriyaibrahim90@gmail.com \\ ${ }^{4}$ wahyu@ringin-contong.com
}

\begin{abstract}
The design of Aluminum metal casting stoves is a research by the method of developing or developing casting stove media. The purpose of this research is to make and design AL metal casting furnaces. This study includes two main things, namely the design of soft metal casting furnaces (Al) and knowing the heat of soft metals (Al) in casting furnaces using infrared thermometer temperature gauges. This metal casting uses Aluminum specimens using LPG heat mechanism. The instrument used to measure temperature is infrared. This tool is used once every minute by firing into soft metal Al to the aluminum melting limit. The results of this study are in the form of casting furnace media design comprising of designing the design, selection of drums with, among others, $350 \mathrm{~mm}$ deamiter, $500 \mathrm{~mm}$ drum height, ram wire making and foundation making. The result of casting shows that LPG initial heat starts from 1 minute generating tghe heat of $95^{\circ} \mathrm{C}$ until the final heat at 80 minutes, which generate the heat of $451^{\circ} \mathrm{C}$.
\end{abstract}

Keywords: Casting furnaces, soft metals (Al), LPG

\begin{abstract}
Abstrak: Rancang bangun tungku pengecoran logam Aluminium merupakan penelitian dengan metode development atau pengembangan media tungku pengecoran. Tujuan penelitian ini adalah untuk membuat dan merancang tungku pengecoran logam AL. Penelitian ini mencakup dua hal utama yaitu rancang bangun tungku pengecoran logam lunak ( $\mathrm{Al})$, mengetahui panas logam Lunak (Al) pada tungku pengecoran dengan menggunakan alat pengukur suhu infrared thermometer. Pada pengecoran logam ini menggunakan spesimen Aluminium mengunakan mekanisme panas $L P G$. Alat yang digunakan untuk mengukur suhu adalah infrared, penggunaan alat inidilakukan tiap satu menit sekali dengan cara ditembakan ke logam lunak Al sampai batas leleh logam aluminium. Hasil penelitian ini berupa Rancang bangun media tungku pengecoran ini meliputi perancangan desain, pemilihan drum dengan antara lain deamiter $350 \mathrm{~mm}$, tinggi drum $500 \mathrm{~mm}$, pembuatan kawat ram, pembuatan landasan. Hasil pada pengecoran menunjukan bahwa panas awal elpiji mulai dari waktu 1 menit panas yang dihasilkan $95^{\circ} \mathrm{C}$ sampai panas akhir pada menit 80 , panas yang dihasilkan $451^{\circ}$.

Kata kunci: Tungku Pengecoran, Logam Lunak (Al), LPG)
\end{abstract}

\section{Pendahuluan}

Pengecoran merupakan salah satu bidang keahlian yang sangat penting dan harus dikuasai oleh Mahasiswa khususnya mahasiswa dari Fakultas Teknik. Sebagian besar diperguruan tinggi memberikan mata kuliah material teknik hanya sebatas teori, sehingga lulusan perguruan tinggi kurang mengetahui atau menguasai skil dalam bidang pengecoran khususnya pengecoran logam. Dengan ketrampilan dan praktek langsung di lapangan, maka mahasiswa akan dapat menggali atau menambah wawasan sehingga mahasiswa siap bekerja pada dunia industri ataupun berwirausaha. Dari segi kelengkapan Labortorium, Fakultas Teknik khususnya Teknik Industri Unhasy kebutuhan sarana alat belum memadai untuk kegiatan praktikum khususnya praktikum mata kuliah material teknik sedangkan materi pembelajaran yang dipakai saat ini terlalu sempit dan bersifat teoritis.

\section{Metode}

Metode Research and Development $(M \& R)$ pada penelitian ini digunakan untuk menghasilkan produk atau benda tertentu, dan berguna untuk menguji keefektifan suatu produk (Sugiyono, 2010: 297). menurut Nana Syaodih (2013: 164), metode penelitian dan pengembangan merupakan suatu langkah langkah atau proses untuk mengembangkan suatu alat atau produk yang berguna bagi masyarakat. Menurut 
pendapat para ahli penelitain di atas dapat dijabarkan dan mempunyai tujuan untuk menyempurnakan, mengembangkan dan meningkatkan mutu pendidikan secara efektifdan terus menerus . Langkah-langkah yang harus dilakukan dalam mengembangkan pendidikan khususnya dalam pengembangan media pengecoran logam logam lunak atau aluminium dapat dilihat pada diagram alur rancangan penelitian tungku pengecoran logam lunak $(A L)$ secara jelas dapat dilihat pada Gambar 1 di bawah ini. ini adalah :

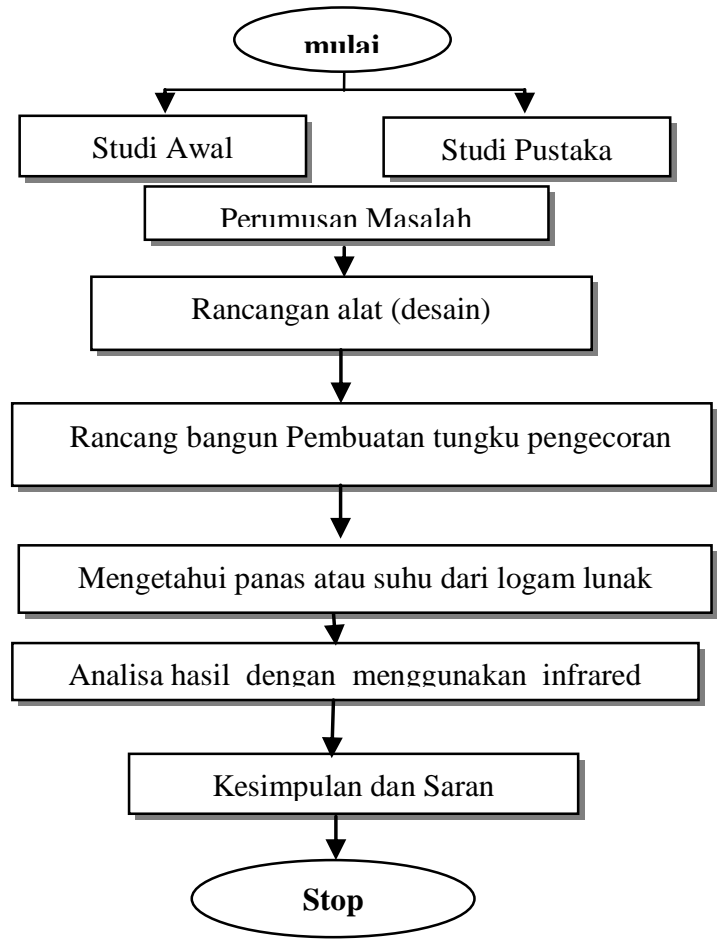

Gambar 1. Tahapan Proses penelitian

Prosedur penelitian pada Gambar diagram alur dapat dijelaskan bahwa masalah yang dihadapi di Laboratorium Teknik Industri Di Unhasy Jombang adalah belum adanya media tungku pengecoran logam lunak yang digunakan pada saat proses pembelajaran khususnya pada saat praktikum sedangkan sarana yang ada sekarang adalah belum lengkapnya kebutuhan peralatan praktik. Sehingga perlu adanya sarana media praktikum berupa media pengecoran logam lunak untuk mendukung proses kegiatan pembelajaran.
Permasalahan di Laboratorium dapat dilihat secara visual dan faktual, maka selanjutnya bisa dijadikan sarana dan prasarana praktikum yang merujuk pada RPS dan silabus .

Langkah awal peneliti meracang desain atau portotype media tungku pengecoran, kemudian pengerjaan membuat tungku pengecoran. Langkah selanjutnya melakukan pengujian pada logam aluminium pada saat proses pengecoran, proses pengecoran dilakukan sampai AL mencair atau meleleh. Tahapan proses pelaksanaan penelitian :

1. Desain media tungkulogam lunak dengan bahan bakar elpiji dengan dimensi antara lain deamiter $350 \mathrm{~mm}$, tinggi drum 500 $\mathrm{mm}$.

2. Konstruksi dari cawan terdapat ditengahtengah sebuah silinder, diding tungku peleburan logam dilapisi dengan bata tahan api atau bahan pengecoran material untuk memproteksi panas dari ruang bakar dapat dilihat pada skema gambar

3. Kebutuhan alat dan bahan yang diperlukan dalam pengecoran antara lain: Alat: mesin las, gerinda, gergaji, sedok semen. Bahan: batang besi cor, besi plat $2 \mathrm{~mm}$, batu dan semen, pasir, kerikil

4. Membangun tungku peleburan logam lunak dengan mekanisme panas dari gas elpiji

5. Proses peleburan aluminium pada awalnya diperlukan bantuan bross untuk membantu mencairkan logam lunak agar mudah terbakar.

6. Penuangan logam cair kedalam cetakan dilakukan setelah logam aluminium mencair untuk meghasilkan produk pengecoran. Logam cair tersebut dituang ke dalam cetakan logam yang berbentuk produk tertentu, seperti wajan, souvenir, atau lainnya.

Komposisi pengecoran serta desain tungku dan gayung dapat dilihat pada Tabel 1 dan Gambar 2 di bawah ini:

Tabel 1. Komposisi dan Satuan dalam Pengecoran 


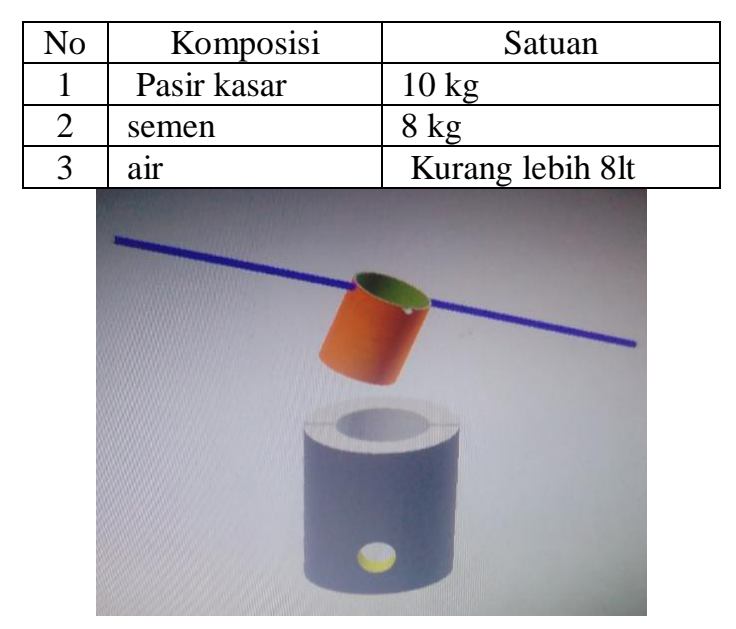

\section{Gambar 2. Desain Tungku dan Gayung Pengecoran Logam}

\section{Hasil dan Pembahasan}

Rangka komponen tungku pengecoran merupakan komponen utama yaiu drum dengan dimensi antara lain deamiter $350 \mathrm{~mm}$, tinggi drum $500 \mathrm{~mm}$. Kerangka ini mempunyai beberapa bagian antara lain: bagian luar yaitu drum yang didalamnya ada bbberapa rakitan atau ram raman kawat yang berfunfsi sebagai otot tungku pengecoran. Bagian samping drum dilubangi diameter $50 \mathrm{~mm}$ untuk masuknya batang atau tangkai kompor gas.

Produk tungku pengecoran logam Aluminium bisa dilihat pada Gambar 3 berikut ini:

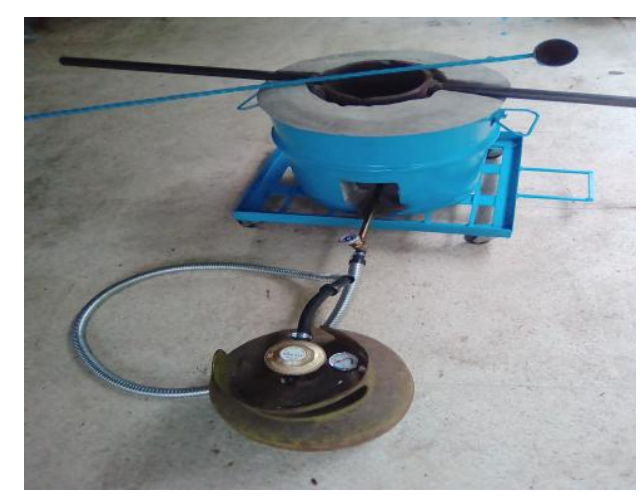

Gambar 3. Produk Tungku Pengecoran Logam Aluminium

Pembuatan media tungku pengecoran dengan menggunakan komposisi bahan material yaitu penelitian dilaksanakan dengan mengambil data pada saat pengecoran logam lunak (AL) dengan menggunakan alat pengukur suhu infrared thermometer, cara menggunakan alat ini yaitu ditembakan ke logam lunak (AL).

Infrah merah pada alat ukur infrared ditembakan ke logam lunak tiap satu menit. Satuan pada alat ukur ini yaitu derajat calcius. Hasil pada pengecoran menunjukan bahwa panas awal elpiji mulai dari waktu 1 menit panas yang dihasilkan $95^{\circ} \mathrm{C}$ sampai panas akhir pada menit 80 , panas yang dihasilkan $451^{\circ} \mathrm{C}$..

Tabel 2 berikut ini ini adalah hasil pengukuran suhu pada logam lunak dengan meggunakan infrared dan thermometer.

Tabel 2. Hasil pengukuran Suhu pada Logam Lunak

\begin{tabular}{|l|c|l|c|}
\hline Panas & $\begin{array}{l}\text { Waktu/ } \\
\text { menit }\end{array}$ & Panas & $\begin{array}{c}\text { Waktu } \\
\text { menit }\end{array}$ \\
\hline $95^{0} \mathrm{C}$ & 1 & $416,9^{0} \mathrm{C}$ & 41 \\
\hline $100^{0} \mathrm{C}$ & 2 & $420,4^{0} \mathrm{C}$ & 42 \\
\hline $119^{0} \mathrm{C}$ & 3 & $422^{0} \mathrm{C}$ & 43 \\
\hline $126,2^{0} \mathrm{C}$ & 4 & $421,9^{0} \mathrm{C}$ & 44 \\
\hline $131^{0} \mathrm{C}$ & 5 & $423^{0} \mathrm{C}$ & 45 \\
\hline $168,3^{0} \mathrm{C}$ & 6 & $425^{0} \mathrm{C}$ & 46 \\
\hline $162,7^{0} \mathrm{C}$ & 7 & $424,7^{0} \mathrm{C}$ & 47 \\
\hline $196,7^{0} \mathrm{C}$ & 8 & $406,2^{0} \mathrm{C}$ & 48 \\
\hline $122,5^{0} \mathrm{C}$ & 9 & $407,2^{0} \mathrm{C}$ & 49 \\
\hline $243,7^{0} \mathrm{C}$ & 10 & $408^{0} \mathrm{C}$ & 50 \\
\hline $251,1^{0} \mathrm{C}$ & 11 & $407^{0} \mathrm{C}$ & 51 \\
\hline $242,1^{0} \mathrm{C}$ & 12 & $421,1^{0} \mathrm{C}$ & 52 \\
\hline $292,3^{0} \mathrm{C}$ & 13 & $422,2^{0} \mathrm{C}$ & 53 \\
\hline $275,2^{0} \mathrm{C}$ & 14 & $414,4^{0} \mathrm{C}$ & 54 \\
\hline $294,5^{0} \mathrm{C}$ & 15 & $425,2^{0} \mathrm{C}$ & 55 \\
\hline $280,8^{0} \mathrm{C}$ & 16 & $416,5^{0} \mathrm{C}$ & 56 \\
\hline $303^{0} \mathrm{C}$ & 17 & $402^{0} \mathrm{C}$ & 57 \\
\hline $332,5^{0} \mathrm{C}$ & 18 & $406^{0} \mathrm{C}$ & 58 \\
\hline $336,9^{0} \mathrm{C}$ & 19 & $413^{0} \mathrm{C}$ & 59 \\
\hline $350,6^{0} \mathrm{C}$ & 20 & $417^{0} \mathrm{C}$ & 60 \\
\hline $356,5^{0} \mathrm{C}$ & 21 & $420^{0} \mathrm{C}$ & 61 \\
\hline $365,7^{0} \mathrm{C}$ & 22 & $433^{0} \mathrm{C}$ & 62 \\
\hline $367,9^{0} \mathrm{C}$ & 23 & $433^{0} \mathrm{C}$ & 63 \\
\hline $373,3^{0} \mathrm{C}$ & 24 & $435^{0} \mathrm{C}$ & 64 \\
\hline $371,6^{0} \mathrm{C}$ & 25 & $434^{0} \mathrm{C}$ & 65 \\
\hline $378^{0} \mathrm{C}$ & 26 & $439^{0} \mathrm{C}$ & 66 \\
\hline $381,4^{0} \mathrm{C}$ & 27 & $437,3^{0} \mathrm{C}$ & 67 \\
\hline $196,7^{0} \mathrm{C}$ & 28 & $437^{0} \mathrm{C}$ & 68 \\
\hline $396,3^{0} \mathrm{C}$ & 29 & $438,1^{0} \mathrm{C}$ & 69 \\
\hline $393,4^{0} \mathrm{C}$ & 30 & $402^{0} \mathrm{C}$ & 70 \\
\hline $397^{0} \mathrm{C}$ & 31 & $404,4^{0} \mathrm{C}$ & 71 \\
\hline $393,1^{0} \mathrm{C}$ & 32 & $433^{0} \mathrm{C}$ & 72 \\
\hline $401,4^{0} \mathrm{C}$ & 33 & $406,4^{0} \mathrm{C}$ & 73 \\
\hline
\end{tabular}




\begin{tabular}{|l|l|l|l|}
\hline $402,8^{0} \mathrm{C}$ & 34 & $402,8^{0} \mathrm{C}$ & 74 \\
\hline $409,2^{0} \mathrm{C}$ & 35 & $419,2^{0} \mathrm{C}$ & 75 \\
\hline $404,6^{0} \mathrm{C}$ & 36 & $424,6^{0} \mathrm{C}$ & 76 \\
\hline $406,5^{0} \mathrm{C}$ & 37 & $436,5^{0} \mathrm{C}$ & 77 \\
\hline $413^{0} \mathrm{C}$ & 38 & $440^{0} \mathrm{C}$ & 78 \\
\hline $414^{0} \mathrm{C}$ & 39 & $445,5^{0} \mathrm{C}$ & 79 \\
\hline $418^{0} \mathrm{C}$ & 40 & $451^{0} \mathrm{C}$ & 80 \\
\hline
\end{tabular}

\section{Simpulan}

Rancang bangun tungku pengecoran ini meliputi perancangan desain, pemilihan drum dengan antara lain deamiter $350 \mathrm{~mm}$, tinggi drum $500 \mathrm{~mm}$, pembuatan kawat ram, pembuatan landasan. Hasil penelitian pengecoran logam ini menggunakan spesimen Aluminium dicairkan sampai titik leleh. Alat yang digunakan untuk mengukur suhu adalah infrared, penggunaan alat ini tiap satu menit sekali dengan cara ditembakkan ke media pengecoran logam lunak sampai batas leleh logam aluminium. Hasil pada pengecoran menunjukan bahwa panas awal elpiji mulai dari waktu 1 menit panas yang dihasilkan $95^{\circ} \mathrm{C}$ sampai panas akhir pada menit 80 , panas yang dihasilkan $451^{0} \mathrm{C}$.

\section{Daftar Pustaka}

Anderson, R.J.. Melting and Casting Alumunium. Lindsay Publications, (reprint of 1925 original), Bradley, IL, 1987, p. 427.

Bala, K.C. (1998). Design and Development of Sand Muller and Standard Sand Rammer.M. Eng. Thesis. Mechanical Engineering Department, Federal University of Technology, Minna, Nigeria.

Bramanta. (2008). Rancangan Dapur Pelebur Untuk Melebur Alumunium Dan Paduannya Dengan Kapasitas $30 \mathrm{~kg}$ Untuk Keperluan Lab.Foundry. USU: Medan.

Daryanto \& Hari Amanto (1999). Logam ferro dan Non Ferro.

Fishman, O.S., (2002). Direct electric heat melting furnaces for aluminum and other non-ferrous metals, Aluminium World, 2(2), 41.

Hardi Sudjana. (2008). Teknik pengecoran
Suryabrata. (2001). Proses Belajar Mengajar.

Lessiter, M.J., (1997). Aluminum crucible melting: small foundry 'models', Modern Casting, 87(12), 50.

Mark E. Schlesinger. (2013). Aluminum Recycling, second edition, Taylor \& Francis Group, Boka Raton.

Smith, L. (1993). Efficient use of electric furnaces in the non-ferrous foundry, Foundryman,86 (4), 131.

Sundari, E. (2011). Rancang Bangun Dapur Peleburan Aluminium Bahan Bakar Gas, Jurnal Austenit, Volume 3 Nomor 1, April 2011, Jurusan Teknik Mesin Politeknik Negeri Siwijaya.

Surdia, Tata. (2000) Pengetahuan Bahan Teknik. Pradnya Paramita, Jakarta

Surdia \& Chijiwa. (1986). Pengetahuan Bahan Teknik. Pradnya Paramita, Jakarta

Winarno, J. (2013). Rancang Bangun Tungku Peleburan Aluminium Berbahan Bakar Padat dengan Sistem Aliran Udara Paksa, Jurusan Teknik Mesin Fakultas Teknik Universitas Janabadra, Yogyakarta. 